\title{
Analysis of Turnaround Time during Casefile and Sample Processing in Forensic Science Laboratory
}

\author{
G. C. Omari ${ }^{1}$, S. V. Manyele ${ }^{2}$, G. Mwaluko \\ ${ }^{1}$ Department of Mechanical and Industrial Engineering, College of Engineering and Technology, University of Dar es Salaam, \\ Dar es Salaam, Tanzania \\ ${ }^{2}$ Government Chemist Laboratory Authority, Dar es Salaam, Tanzania \\ Email: omarigloria2@gmail.com,gmwaluko@yahoo.com,gcla@gcla.go.tz,sammanyele@gmail.com
}

How to cite this paper: Omari, G.C., Manyele, S.V. and Mwaluko, G. (2018) Analysis of Turnaround Time during Casefile and Sample Processing in Forensic Science Laboratory. Engineering, 10, 43-73.

https://doi.org/10.4236/eng.2018.102005

Received: January 15, 2018

Accepted: February 25, 2018

Published: February 28, 2018

Copyright $(9) 2018$ by authors and Scientific Research Publishing Inc. This work is licensed under the Creative Commons Attribution International License (CC BY 4.0).

http://creativecommons.org/licenses/by/4.0/

\begin{abstract}
Turnaround time (TAT), is the total time interval from when a request for forensic laboratory analysis is received until when the results are collected by the client. The performance of the forensic science laboratory (FSL) is affected by extended TAT in the case-file and sample processing steps necessitating critical analysis reported in this paper. The total TAT was obtained as the sum of measured time interval for each work station (six of which were studied). Extended TAT leads not only to customer complaints, but also paves way for customers to seek for services from competitors, leading to lost competitive edge for the FSL. This study was conducted to establish the baseline data on TAT (between 2014 and 2015) to enable implementation of corrective actions. Six casefile processing steps were identified for which starting and completion times were recorded in dates, giving TAT values in days. The TAT data for each step was collected as each case file is processed and analyzed separately using statistical analysis while comparing the data for the two years (Y2014 and Y2015) and among three forensic science laboratory disciplines (biology/DNA, chemistry and toxicology). The overall turnaround time (TTAT) was the highest for forensic biology/DNA compared to forensic toxicology and chemistry. The analysis time $\left(T A T_{2}\right)$ was the longest of all six case-file processing steps. Using Pareto analysis, the three major steps necessitating root-cause analysis and intervention to minimize TAT were analysis turnaround time $\left(T A T_{2}\right)$, report collection time $\left(T A T_{6}\right)$ and report review time $\left(T A T_{4}\right)$. It was concluded that the causes for extended TAT are within control by the FSL management, although financial and human resources are required.
\end{abstract}




\section{Keywords}

Turnaround Time, Forensic Science Laboratory, Forensic Biology/DNA, Forensic Chemistry, Forensic Toxicology, Statistical Analysis, Pareto Analysis, Root Cause Analysis

\section{Introduction}

Sample management in forensic science laboratory is part of process control, one of the essentials of a quality management system, implemented to ensure that the samples received are handled within the right time without jeopardizing the requirements needed to produce accurate test results in the valid time called the turnaround time (TAT). The term TAT describes the interval when a test is requested to the time when the client or the requesting authority collects the results [1] [2]. In this study, data were collected and analyzed as case files and samples are continuously received at each step to determine the bottlenecks leading to extended turnaround time.

The forensic science undertaken by the FSL covers a wide range of scientific disciplines using scientists of a wide range of skills. The main function of the FSL is to provide impartial scientific evidence for use in the court of law. This is usually as a result of a police inquiry, where scientific evidence is needed to help the police with their investigations. The FSL's current product portfolio includes world first advances in DNA interpretation, automated DNA profiling with software solutions for data analysis, forensic chemistry and toxicology analytical outputs. World class service FSLs are characterized by their efforts towards reducing the total time required for reporting the results of investigations, also called timeliness. The difference is, timeliness of results reporting has not been a major research focus in forensic science but in clinical laboratories [3] [4] [5]. Timeliness which is expressed as the TAT is often used by the FSL as the benchmark for laboratory performance. A short laboratory analysis step TAT helps the scientists to start interpretation of the test results earlier for a particular case-file which leads to client's satisfaction. Analytical results and interpretation are certainly affected by delays in sample processing [6].

Currently, accuracy, reliability and timely reporting of laboratory test results are considered an important aspect of the services provided by the FSL. Faster turnaround time can make big investigative difference. Moreover, the judiciary wants reports as rapidly as possible to allow legal proceedings to start. It has also been shown that outcomes in certain situations (such as criminal proceedings) have been affected by timely reporting of forensic laboratory tests results [7]. Turnaround time includes the pre-analytical phase (expressed in this study as initial administrative processes), analytical and post-analytical time (expressed as report writing, report review, report approval and collection by client), which implements wider categorization of the processes than literature reports [1] [8] 
[9]. Increased attention to investigators and the judiciary needs is demonstrated by efforts to improve the quality of the entire services provided, e.g., reduction of laboratory TAT, although delays outside the laboratory are also critical. The availability of the results from a forensic science laboratory in definite time increases the client's satisfaction and also proves the forensic scientists' efficiency. The laboratory turnaround time can also be defined differently according to the test type (fast track versus routine), type of analysis and institution. TAT is one of the most noticeable signs of laboratory service and is often used as a key performance indicator of laboratory performance.

Most FSLs are constantly pressurized to deliver results more quickly. Recent studies have reported that most clients' dissatisfaction with laboratory services resulted from the turnaround time of results. The analytical phase of testing often contributes significantly more to the total TAT than both the pre-analytical and post-analytical phases. This study defines pre-analytical phase as time from submission of a written request and samples to the time laboratory analysis commences. Unfortunately, many steps in the pre-analytical phase, such as specimen collection and transport to the laboratory, are often beyond the laboratory's direct control, and are not included in this study.

Sample preparation is a pre-analytical process that can be controlled by the laboratory [10]. Thus, it is included in this analysis as part of laboratory analysis time. A viable option to improve sample handling in the FSL is automation. Installation of total laboratory automation systems has been shown to dramatically improve laboratory TAT and throughput. However, even with automation, centrifugation is still a lengthy step in specimen processing that can take even longer than the analysis of the specimen (for example, toxicological analysis). The sample preparation for DNA testing, for instance, is also lengthy compared to forensic chemistry analysis. The overall TAT was broken into 6 steps, that is: pre-analytical phase (initial administrative procedures), analysis time (once the samples are received by analysts), report writing phase, report review time and report approval process [10]. The report collection delay by clients was also analyzed in order to assist in debottlenecking the case flow management problems in the courts.

The objective of this study was to determine the TAT of the FSL processes and to evaluate the contribution of six analytical phases (namely the initial administrative processes, analysis time, reporting writing review report, approval of report and report collection by client).

\section{Literature Review}

This study reviewed the literature regarding FSLs turnaround time, focusing on the different definitions, measures, association with analytical outcomes and approaches to minimize TAT [1]. In particular, the study focuses on analysis of turnaround time during the sample management and case-file processing. One of the most visible and talked about areas of laboratory service is how fast a test 
result is reported [5] [6]. Literatures reveal a variety of different approaches to the definition of TAT. The TAT can also be classified by test (e.g., DNA test, forensic toxicology or chemistry), priority (e.g., urgent or routine), population served (e.g., criminal, civil or disaster victim identification (DVI) cases) and the activities included [11].

In addition, given that non-analytical delays could make the largest fraction of the TTAT [12], TAT has been considered for intra-laboratory activities only. In the DVI, for example, type and procedure of sample collection and managing the sample causes delays in interpretation of results by FSL. The effects of TAT have been studied in hospitals, with correlations being drawn between the length of stay of the specimen or sample and performance of the emergency department [1]. As a result, TAT is often considered the most significant measure of a laboratory's performance.

TAT has been described in a number of ways by the researchers. The "total testing cycle" describes TAT as consortium of nine steps: ordering, collection, identification, transport, preparation, analysis, reporting, interpretation and action. While clinicians consider TAT from the time the test is ordered to results reporting, laboratory professionals usually use specimen receipt to reporting of results as TAT [13]. A recent assessment of laboratory turnaround time indicated that analysis of this time interval has helped in defining the cause of delay, which is then monitored by the improvement in TAT via identification of cause factors and problem solving towards reduced TAT [14].

Reducing TAT comprise of determined actions in combination or in isolation such as recognizing and quantifying the components of the TAT, eliminating non-productive steps in the laboratory operations process, categorizing the tired rate, measuring and eliminating errors, and reducing batch size. Many researchers have reported various methods to shorten laboratory TAT [15]-[21]. A real-time TAT monitoring system, have been reported in literature [22]. Recognizing what makes up the turnaround time and quantifying it is a first step in minimizing TAT. Non-analytical delays, such as transporting and reporting delays, are the main causes of extended laboratory TAT [12] [23]. The second action involves removal of all of the non-productive or uneconomical steps in the process. After identifying the overall turnaround time there is a need to eliminate all activities that do not add value to clients. Reduction of TAT needs to have the work flowing through the FSL processes at the same frequency as the clients demand, for instance, consideration of shift system or emergency service and out-sourcing of analysis (referred samples).

Although in the past, laboratories have focused on TAT for performance assessment, a more appropriate method of benchmarking might be to set analytically driven TAT targets and assess performance as the percentage of results achieving this goal [24]. Extended TAT leads to complaints from clients [22], while adequate TAT goes unremarked [25]. Despite advances in analytical technology, many laboratories have difficulties improving their TATs. The judiciary 
on the other hand, is interested in service quality, which encompasses availability of results, cost, relevance and timeliness [26]. Analysts, however, desire a rapid, reliable and efficient service delivered at low cost [27].

Many health laboratories have judged general quality of services by means of TATs measured in minutes while in FSL the TATs are measured in days. However, TAT diverges greatly based on individual FSL and the category of test under consideration, reduction of which is a key towards laboratory performance improvement [24]. Hence, short TAT is important both from a forensic science and commercial point of view. This issue is very important and in general, laboratories do not stress enough on its significance, while timely criminal justice decisions depend on timely reporting.

Other methods on how to improve TAT is explained by first elaborating the multifactorial analysis which shows TAT to be affected by a variety of factors that can be placed in two categories. The factors affecting TAT include the nature of the FSL staff, extent of computerization, method of sample transport and FSL organization and management in general [28] [29]. Process mapping to identify rate-limiting steps within the laboratory is useful and simple improvements should be considered before complex steps such as total laboratory automation and computerization are considered [15] [30]. Improving the specific components of TAT will finally reduce the overall TAT.

There is no publicly available resource which provides laboratory-specific turnaround times for FSL. This lack of information may be due to variations in the methods of calculating turnaround times among laboratories, caused by differences in SOPs, administrative settings and legal requirements and also due to lack of resources to track TAT in FSLs. Reasons for extended TAT from literature are wide in nature. Among other factors from the literature, which have been found to affect TAT of forensic laboratory, it is the sample size. It has been reported that results were available sooner in general forensic laboratory than in an appellate forensic laboratory and in smaller rather than larger laboratories with more than three disciplines of forensic science [5].

\section{Methodology}

\subsection{Study Area}

Case-file influx into GCLA are processed within three departments, whereby 123 (12.1\%) were from Chemical Management Department (CMD), 112 (11.1\%) from Product Quality Services (PQSD) and 778 (76.8\%) from Forensic Science and DNA Services (FSDS) making a total sum of 1013 in Y2014. The focus of this study was on TAT for the case-files processed in FSDS, due to the increased demand and attention by the public and justice and investigation departments in the country. Distribution of case-files into FSDS or FSL disciplines was further analyzed, to establish root causes. The number of case-file used to analyze TAT in the FSL was 778 out of which 350 (45.0\%) were processed in forensic biology/DNA laboratory; $177(22.8 \%)$ and 251 (32.3\%) on the other hand, were 
processed in forensic chemistry and toxicology laboratory, respectively. For each analysis, the number of casefiles is reported since in some cases initial and/or completion dates were missing, changing the sample size.

\subsection{Process Description}

\subsubsection{First Route-The Analysis Instructions}

The client or the Zonal laboratory sends the sample or the crime scene evidence to the headquarters, with written request for analysis, as shown in the process flow chart in Figure 1. This is normally accompanied by necessary documents, identifying the exhibits and stating the requested services and the address from the legally authorized agencies, institutions or departments. After evaluating the evidence or sample for acceptance, the sample receiving officer (SRO) marks the evidence using the stipulated SOPs and regulations, followed by filling the sample analysis request (SAR). The dully filled forms are sent to the CGC's office for administrative procedures and request for instructions. Meanwhile, the samples or exhibits are sent to the exhibit room where the laboratory manager is the custodian (while observing the chain of custody and sample integrity).

The CGC's office makes copies and stores the administrative records (that is, information not resulting from evidence examination, for example, vouchers and requests for lab testing). After scrutiny and vetting of the submitted request, the CGC sends the first instructions in relation to applicability of tests and



Figure 1. Sample management and reporting for casefiles in the FSL. 
responsible laboratory discipline(s) for the specified case to the Directorate of Forensic Science and DNA Services (DFSDS). The DFSDS determines the probative value of the sample or evidence and assigns to the respective FSL discipline (that is, forensic chemistry, forensic biology/DNA and/or forensic toxicology). If additional information or sample is required before accepting the evidence, the appropriate agency is contacted to obtain the information or extra sample needed.

As a supervisor, the laboratory manager evaluates the submitted case information for each item of exhibit or sample. During the evaluation process, the communication log and case notations is created. The laboratory manager, prepares the schedules for analysis and assigns one or two analysts the analysis task and confirms the appropriate or targeted completion date. The analysis commences if all conditions have been met (e.g., all samples/exhibits, reagents and machine availability). Each evidence item or sample from the evidence or main sample is normally given a unique identification number, in addition to the laboratory number provided by the SRO at the beginning.

\subsubsection{Laboratory Analysis Report Writing and Review}

The scheduled analysis range from determining only the presence of chemical, poison, semen, saliva, or blood on an item as a complete analysis request or a presumptive test. It may be followed by the instrumental analysis after recovery or extraction procedures. For the purpose of comparison with victims, elimination samples, and/or suspects may be required. The decision of what analyses are to be performed is made by a member of the exhibit sign-in team in the respective discipline of FSL. The turnaround time for laboratory analysis, starts when the analysis commences until when it is completed ready for report writing. After report writing by the analysts, the report is submitted to the manager for review before an approval process begins. All the timing is recorded on the SAR form, modified to suit data collection during this research work.

\subsubsection{Second Route-The Approval Process}

Evidence report with conclusion is completed by the analyst before a comparison or review is completed by the laboratory manger. Information of the examined exhibit, records and data results are written by the analyst. It is then forwarded to the laboratory manager for interpretation as the draft report (denoted as report review process). This is followed by sending the reviewed report to the Director requesting for the first approval. The evidence report describes the examination of any evidence that was submitted and the statistical statements of the respective FSLs results of the evidence. It is expected that administrative documents and respective analytical results documented are marked with a case number on each page. The director performs the technical and administrative review on casefile and related analytical results and creates copies of reports from the draft report (paper work) for certification. If corrections are made on hard copy examination documentation and interpretation, a 
strike-through must be drawn through the error; and initialed and dated by the director by making the changes. The director forwards the report requesting for second approval by the CGC, who scrutinizes clarity and accuracy of the reports, avoiding overly technical terminologies and misleading statements. The CGC approves the report as the third report approval. This is followed by forwarding the approved report to the SRO after copies are made and documented, waiting for collection.

The process flowsheet shown in Figure 1 has two main paths which are the instruction and approval paths, described above. On the other hand, the sample/exhibit follows its own path parallel to the documents during the first path, indicated by dotted lines in Figure 1. This flow ends at the laboratory after analysis is completed. Based on sample and case-file processing as shown in Figure 1 , the time delay to accomplish each task at a given work station for both paths (instructive and approval) contributes to the overall or total turnaround time (TTAT).

\subsection{Identification of the Components of Turnaround Time during Case-File Processing}

Figure 2 shows the flow diagram for sample management and case-files processing system within FSL for the three forensic science laboratories. The assessment was implemented for each laboratory discipline, that is, toxicology, chemistry and Biology/DNA analysis, because the three disciplines perform analysis using different SOPs, techniques and equipment. The steps which do not depend on discipline were combined and an overall TAT determined, such as $T A T_{1}, T A T_{5}$ and $T A T_{6}$, as shown in Figure 2. Figure 2 shows the study design and the synthesis of workstations showing sample movement after submission by the client (police investigators or zonal laboratory) and also flow of documentation, chain of custody and assignment/approval by the manager, director and CGC, with the respective TTAT components. Note that the $T A T_{s}$ for sample movement is not included in the analysis of TTAT, since it moves parallel to the $T A T_{1}$.

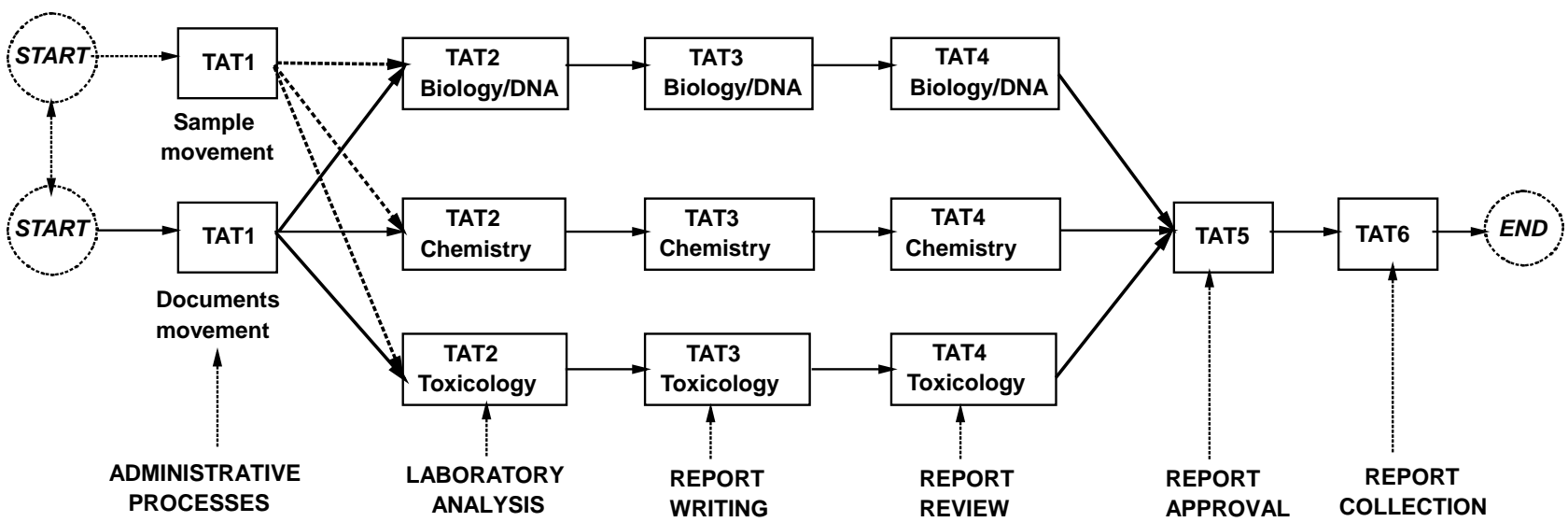

Figure 2. Identification of the turnaround time in different case-file processing steps for the three different laboratory disciplines. 


\subsection{Determination of Turnaround during Case-File Processing}

Based on sample and case-file processing as shown in Figure 1, the time delay to accomplish each task at a given work station contributes to the overall or total turnaround time (TTAT). In this study, the components of the TTAT were analyzed so as to give an insight of the critical control points or bottlenecks in the overall management of the FSL. Table 3 summarizes the datasheet to be used for determination of TAT and its components. In this analysis, about twenty action points can be evaluated for time delays, leading to $T_{1}, T_{2}, T_{3}, \cdots, T_{19}, T_{20}$, time interval measurement points in the whole process, as shown in Table 1 . It should be noted that time intervals for each step were determined based on the starting and completion dates. Out of 20 action points, time intervals were combined to yield 6 steps from the time samples and written request for analysis are received at the SRO (denoted in Figure 2 as $S T A R T$ ), to the time analytical report is collected by the client (denoted as $E N D$ ).

Table 2 shows the major activities in the case-file processing steps and the group of delays included for each step to define six TAT components studied in details.

Furthermore, the shorter TAT will indicate more productive work station. Thus, six steps of case-file processing cycle (also referred to as components of the TTAT) were identified and analyzed as listed in Table 2. For each interval in Table 1 and Table 2, data was collected for a number of case-files, denoted as $\mathrm{N}$, as repetitive cycles, leading to a time series of TAT values. Statistical analysis lead to average values, standard deviation, etc. PDFs and CDFs. Variations in TAT from case-file to another were measured by standard derivation, used as a measure of TAT repeatability or reproducibility. Moreover, the span of TAT data (a measure of variability and a measure of the problem of extended TAT) was presented using probability density function (PDFs) and cumulative distribution functions (CDFs).

\subsection{Turnaround Time Analysis}

Turnaround time analysis was accomplished determination of actions to be performed, for which turnaround times for six actions were determined and recorded. The total TAT for a Forensic science case-file (also called the actual time) was determined as per Equation (1):

$$
T T A T=\left(T A T_{1}+T A T_{2}+T A T_{3}+T A T_{4}+T A T_{5}+T A T_{6}\right)
$$

where $T A T_{1}=$ time for initial administrative processes, $T A T_{2}=$ analysis time, $T A T_{3}=$ report writing time, $T A T_{4}=$ report review approval $1+2$ time, $T A T_{5}=$ final port approval, and $T A T_{6}=$ report collection delay. In this study, the number of casefiles attended within the FSL, was $N_{1}=778$ for the year 2014 and $N_{2}=$ 690 for the subsequent year 2015. Using the total turnaround time and knowing that TTAT represents time to complete one case-file, the productivity of FSL for laboratory analytical process (which is a measure of throughput, number of case-files per day) denoted as $\lambda_{\mathrm{cp}}$, was estimated as per Equation (2): 
Table 1. Determination of TAT in FSL based on sample and case-file processing.

\begin{tabular}{|c|c|c|c|}
\hline $\begin{array}{l}\text { Date of case-file movement } \\
\text { from one work station to } \\
\text { another }\end{array}$ & Symbol & Formula & Definition of time interval \\
\hline Date in & A & - & - \\
\hline Sample receiving date & $\mathrm{E}$ & - & - \\
\hline Date SRF submitted to CGC & $\mathrm{F}$ & $\mathrm{t}_{1}=\mathrm{F}-\mathrm{E}=\mathrm{F}-\mathrm{A}$ & Sample receiving officer to CGC \\
\hline Date released by CGC & I & $\mathrm{t}_{2}=\mathrm{I}-\mathrm{F}$ & Office of the CGC \\
\hline Date submitted to director & $\mathrm{J}$ & $\mathrm{t}_{3}=\mathrm{J}-\mathrm{I}$ & CGC to Director \\
\hline $\begin{array}{l}\text { Date instructions } \\
\text { released by director }\end{array}$ & $\mathrm{L}$ & $\mathrm{t}_{4}=\mathrm{L}-\mathrm{J}$ & Director's Office \\
\hline $\begin{array}{l}\text { Date instructions } \\
\text { released by manager }\end{array}$ & $\mathrm{N}$ & $t_{5}=N-L$ & Instructions \\
\hline $\begin{array}{c}\text { Date samples received } \\
\text { by analyst }\end{array}$ & $\mathrm{P}$ & $t_{6}=P-N$ & Manager to Analyst \\
\hline Date analysis commenced & $\mathrm{R}$ & $\mathrm{t}_{7}=\mathrm{R}-\mathrm{P}$ & $\begin{array}{l}\text { Sample receipt by analyst, } \\
\text { start of analysis }\end{array}$ \\
\hline Date analysis was completed & S & $\mathrm{t}_{8}=\mathrm{S}-\mathrm{R}$ & Sample Analysis time \\
\hline Date report completed & $\mathrm{V}$ & $\mathrm{t}_{9}=\mathrm{U}-\mathrm{S}$ & $\begin{array}{l}\text { End of Sample Analysis, } \\
\text { start data interpretation }\end{array}$ \\
\hline $\begin{array}{l}\text { Date report submitted } \\
\quad \text { for review }\end{array}$ & $\mathrm{W}$ & $\mathrm{t}_{10}=\mathrm{V}-\mathrm{U}$ & Start of report write up \\
\hline Date review comments availed & $\mathrm{X}$ & $t_{11}=W-V$ & Complete report, submit for review \\
\hline $\begin{array}{l}\text { Date report submitted } \\
\text { for approval }\end{array}$ & $\mathrm{Y}$ & $t_{12}=X-W$ & Time to review \\
\hline Date approved by manager & $\mathrm{Z}$ & $t_{13}=Y-X$ & Report Revision time \\
\hline $\begin{array}{l}\text { Date report submitted for } \\
\text { approval to director }\end{array}$ & $\mathrm{AA}$ & $t_{14}=Z-Y$ & $\begin{array}{l}\text { Time for approval by } \\
\text { Laboratory Manager }\end{array}$ \\
\hline $\begin{array}{l}\text { Date report approved } \\
\text { by director }\end{array}$ & $\mathrm{AB}$ & $\mathrm{t}_{15}=\mathrm{AA}-\mathrm{Z}$ & $\begin{array}{l}\text { Time for approved report } \\
\text { to reach FSL Director }\end{array}$ \\
\hline $\begin{array}{l}\text { Date submitted for } \\
\text { approval to CGC }\end{array}$ & $\mathrm{AC}$ & $\mathrm{t}_{16}=\mathrm{AB}-\mathrm{AA}$ & Director's approval time \\
\hline Date approved by CGC & $\mathrm{AD}$ & $t_{17}=A C-A B$ & $\begin{array}{l}\text { Time for approved report } \\
\text { to reach CGC }\end{array}$ \\
\hline Date report received by SRO & $\mathrm{AE}$ & $\mathrm{t}_{18}=\mathrm{AD}-\mathrm{AC}$ & $\begin{array}{l}\text { Final Approval time } \\
\text { (CGC's approval) }\end{array}$ \\
\hline \multirow[b]{2}{*}{ Date report collected by client } & \multirow[b]{2}{*}{$\mathrm{AF}$} & $\mathrm{t}_{19}=\mathrm{AE}-\mathrm{AD}$ & $\begin{array}{l}\text { Final approved report } \\
\text { to reach SRO }\end{array}$ \\
\hline & & $\mathrm{t}_{20}=\mathrm{AF}-\mathrm{AE}$ & $\begin{array}{l}\text { Time report received by SRO until } \\
\text { collection by client (time approved } \\
\text { report stays at SRO) }\end{array}$ \\
\hline
\end{tabular}

$$
\lambda_{c p}=\frac{1}{T T A T}
$$

The theoretical turnaround time $T A T_{t h}$ (total time for value added activities) 
Table 2. Major groups of activities during case-file processing in the FSL.

\begin{tabular}{|c|c|c|c|}
\hline $\begin{array}{c}\text { TAT } \\
\text { symbol }\end{array}$ & Major activities or processes & $\begin{array}{l}\text { Time interval } \\
\text { (from Table 1) }\end{array}$ & $\begin{array}{l}\text { TAT } \\
\text { (days) }\end{array}$ \\
\hline $\mathrm{TAT}_{1}$ & $\begin{array}{l}\text { Initial administrative processes } \\
\text { 1) Sample analysis request submission } \\
\text { 2) Request for instructions from CGC } \\
\text { 3) Instruction to Director of FS laboratory } \\
\text { 4) Director's instructions to Laboratory Manager } \\
\text { 5) Assigning analyst by Laboratory Manager }\end{array}$ & $\mathrm{N}-\mathrm{E}$ & $\mathrm{T}_{5}-\mathrm{T}_{1}$ \\
\hline $\mathrm{TAT}_{2}$ & $\begin{array}{l}\text { Analysis time, which comprises of: } \\
\text { 1) Commencement of laboratory analysis } \\
\text { 2) Preliminary tests and sorting } \\
\text { 3) All processes in sample preparation } \\
\text { 4) Completion of the analysis }\end{array}$ & $S-R$ & $\mathrm{~T}_{8}-\mathrm{T}_{6}$ \\
\hline $\mathrm{TAT}_{3}$ & $\begin{array}{l}\text { Starts when analysis is completed until report } \\
\text { writing is completed } \\
\text { Report writing process includes } \\
\text { 1) Drafting the report } \\
\text { 2) Synthesizing the findings and concluding the } \\
\text { forensic results }\end{array}$ & $V-S$ & $\mathrm{~T}_{11}-\mathrm{T}_{8}$ \\
\hline $\mathrm{TAT}_{4}$ & $\begin{array}{l}\text { Report review time, which starts from the time } \\
\text { when report writing is completed until when the } \\
\text { report is submitted reviewed by the Laboratory } \\
\text { Manager }\end{array}$ & $\mathrm{W}-\mathrm{V}$ & $\mathrm{T}_{15}-\mathrm{T}_{12}$ \\
\hline $\mathrm{TAT}_{5}$ & $\begin{array}{l}\text { First approval from the Director followed by } \\
\text { finally approved by CGC. The TAT is the time } \\
\text { from when the report is submitted to the } \\
\text { Director for approval to the time the } \\
\text { report is approved by CGC. }\end{array}$ & $\mathrm{AD}-\mathrm{W}$ & $\mathrm{T}_{17}-\mathrm{T}_{16}$ \\
\hline $\mathrm{TAT}_{6}$ & $\begin{array}{l}\text { Report collection delay involves time from the } \\
\text { date the report is approved by CGC, transferred } \\
\text { to SRO to the time the report is collected } \\
\text { by the client. }\end{array}$ & $\mathrm{AF}-\mathrm{AD}$ & $\mathrm{T}_{20}-\mathrm{T}_{17}$ \\
\hline
\end{tabular}

processes during which a sample is attached to the instrument) that is TAT analysis determined as per Equation (3):

$$
T A T_{\text {th }}=\left(T A T_{2}+T A T_{3}+T A T_{4}+T A T_{5}\right)
$$

The TAT for non-productive time, $T A T_{n p}$, was determined as per Equation (4):

On the other hand, the turnaround time performance ratio $\left(T_{P R}\right)$ was determined using Equation (4):

$$
T_{P R}=\frac{T T A T}{T A T_{t h}}
$$

\section{Results and Discussion}

\subsection{Ranks of Analysts Performing Analytical Work for the Reported Casefiles}

Figure 3 shows the distribution of the case-files processed by different ranks of 

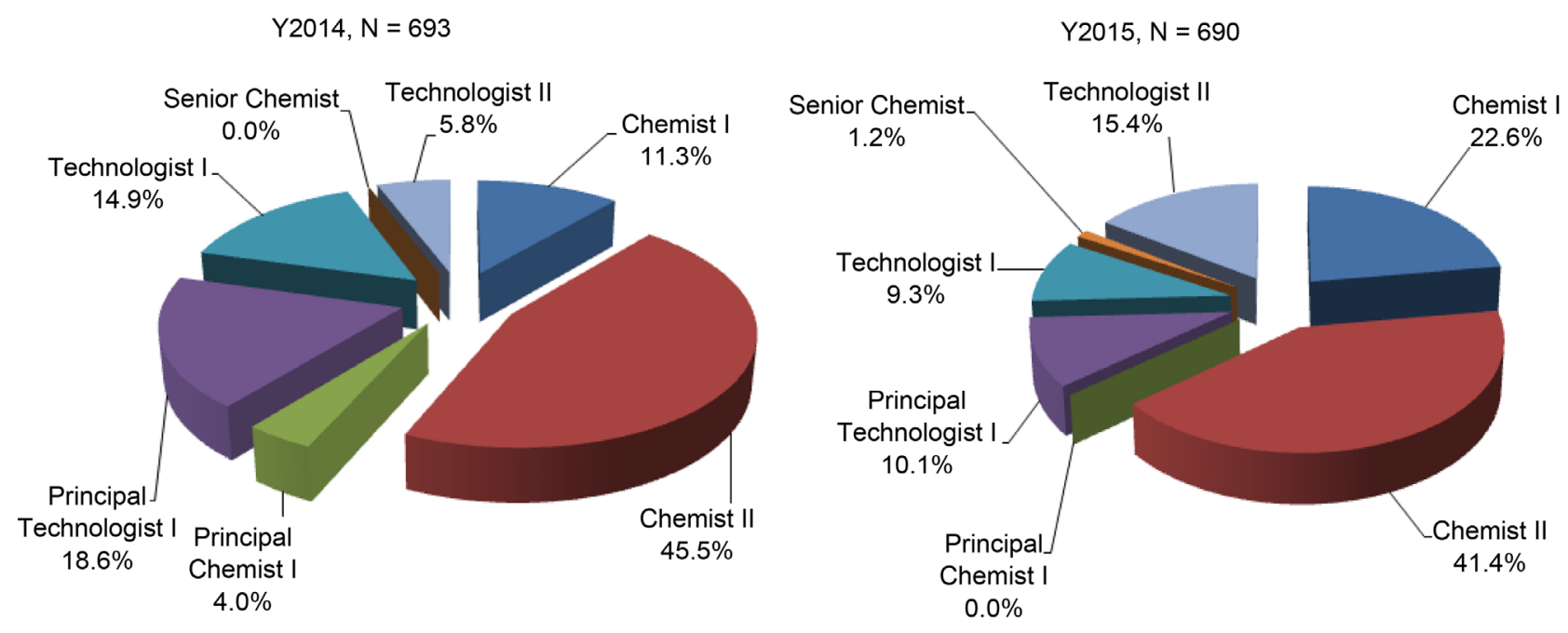

Figure 3. Frequency distribution of case-files attended by different ranks of analysts.

employees during laboratory analysis for the two years studied. The lower cadres of Chemist II and Technologist II which are always attached to the Senior and Principal chemists as part of training and capacity building, forms the workhorse of the FSL, processing larger portion of case-files in both Y2014 and Y2016. Results show that the pr3incipal chemists contributed very small $t$ the case-files processing in the two consecutive years. It is recognized that the higher the rank, the higher the expected engagement in the laboratory processes. Such employee will increase innovation, productivity, and bottom-line performance while reducing costs related to hiring and retention in highly competitive talent markets of FSLs. This is different from the observation made in the FLS, whereas, the higher ranks contributed very little. This is attributable to more administrative responsibilities for the professional staff, which become least engaged with laboratory analytical processes.

In addition, higher ranks may have a critical effect on the performance of the FSL, including reduction in TAT. While it is the responsibility of the manager of the laboratory to supervise all the processes, they are eventually excluded from bench work as analysts. Moreover, they increasingly play a role in training of new laboratory staff both informally and formally.

\subsection{Initial Administrative Procedures' Time}

Figure 4 shows the PDF of turnaround times recorded for the initial administrative processes prior to commencement of laboratory analysis. The PDF presents the data collected using 709 and 690 case-files assessed in Y2014 and Y2015, respectively. The average time taken to complete the initial administrative procedures was reduced from 3.4 to 2.4 days from Y2014 to Y2015. Standard deviation shows that in Y2015, the data was more reproducible indicating improved supervision of the processes.

Due to laxity in the movement of the forms and readiness to issue instructions, the average time delay before analysis can commence was about 2.4 days. 


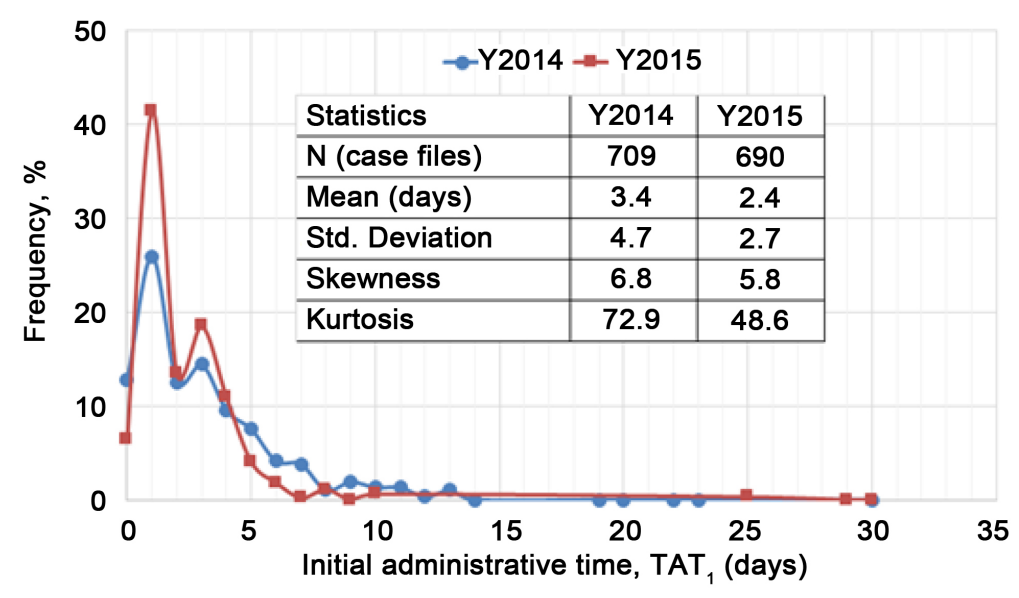

Figure 4. The PDF of initial administrative processes' turnaround time.

Improvements should be made to reduce this time to 1 day. This delay contributes strongly to the total TAT, which can be minimized easily by making changes and improvements in the way administrative duties are carried out. Further analysis of the initial administrative delay data shows that $S_{k}=6.8$ and 5.8 for Y2014 and Y2015, respectively, indicating that there exists few data points with higher TAT values at this step in Y2015 than in Y2014. Positive skewness indicates leading to an extended tail towards the right covering longer TAT in the PDF shown in Figure 4, which were however, at very low frequency. A higher standard deviation for data used in Figure 3 indicates stronger variations in the time consumed by initial administrative process once the samples and requests for analysis are received to the FSL, which indicates an inconsistence in the management of case-files during non-laboratory operations, which shows improvements in Y2015.

There are five administrative steps in the process denoted as the initial administrative process, as per Figure 1. That is, sample analysis request (SAR)-a point of action when the SRO receives the request from the requesting authority; request for instructions-when the SRO submits the request to the CGCS' office; instruction-1-instructions given by CGC including the distribution of the request to the respective directorate; instruction-2-when the director instructs the manager of the respective laboratory on the type of analysis to be done or method to be employed on the specific case and instruction-3-which is the actual assignment given to the analyst by the manager before laboratory analysis commences. It is the distribution of work depending on the skills and competence and facilities available. The observed modal value of 1 day indicates that most case-files take one day to complete the initial administrative processes.

In this part of process there are several activities that may cause time delay such as the need for sample receiving officer (SRO) to have a good understanding of the organogram and the job description of each head of laboratory in the respective departments. This will enable the SRO to direct appropriately the requests coming from the clients. Also, there should be enough staff for distribut- 
ing the samples and documentation to the respective departments while the other personnel attend the arriving clients submitting new requests and samples at the same time. Another challenge causing delay includes forms and requests from the CGC's office after the first instruction is given (as per Figure 2). In addition, in case of a high sample influx to the FSL, there will be a delay in forwarding other requests due to high manpower demand (Manyele, 2017). This may result in backlog where pending requests of the previous day(s) may pileup and remain unattended (Omari et al., 2017). As a result, the TAT is extended. Documentation and administrative procedures cause additional time delay, due to quality management requirements for record keeping, as well as a need for maintaining chain of custody and to make sure that all procedures are followed. Another procedure causing extended TAT is that of categorization of the specific cases and directing case-files into the related department or section which require going through the history of the case notes. Case notes accompanying the case-files in FSL should be recorded and presented in such a manner that forensic scientists competent in the same field, may instruct the analysis correctly. If applicable, the case notes should direct the instrumental method to be used in acquiring the required data.

Higher workload in the CGC's office may cause delay in attending the forensic science case-file, especially when there is a dramatic increase in both volume and complexity of the case-files which require accomplishment by multiple employees, whereas there are only few staff available. In addition, inefficient and uncertain forensic science regulations can be the greatest cause of delay such as regulations of sample management and laboratory information system. Elimination of the delays in administrative steps can be addressed in different ways. Staffing of experienced staff in the SRO unit by increasing number of staff, preferably technical personnel those that are conversant of the type of cases that are received within the FSL is suggested. The management in coordination with the SRO and records manager can set performance measures and goals for assessing the effectiveness of records management for case-files within various laboratory settings, together with establishing effective and applicable policy and regulations and records management procedure documents for use as reference materials.

Regular audit of such processes in the $T A T_{1}$ step using relevant data can help in evaluating the efficiency of the forensic science laboratory to allow corrective measures to be taken. This could help in providing better services to the investigators, prosecutors and the judiciary. The tasks performed in the pre-analytical and post analytical area such as opening sample/evidence bags and accessioning samples should be performed by experienced technical staff including experienced laboratory technologist and chemists.

\subsection{Sample Movement Turnaround Time}

During initial administrative procedures samples are also transferred to the re- 
spective laboratory managers to allow proper storage and planning of the analytical work. This process takes place in parallel, shown using dotted lines in both Figure 1 and Figure 2. Being a parallel process, this step is not included in the determination of total turnaround time, TTAT (as per Equation (1)). Figure 5 shows the PDF of sample movement turnaround time data for the two consecutive years. The average $T A T_{s}$ was observed to increase from 14.7 to 58.3 days, being longer than $T A T_{1}$. Different from $T A T_{1}$, the $T A T_{s}$ data follows logarithmic $\mathrm{PDF}$, with long extended tails to the right. Two peaks were identified for the $T A T_{s}$ data, that is, a larger number of case-files whose corresponding samples are transferred within 1 day, and another peak at $T A T_{s}=5$ days and 7 days for Y2015 and Y2014, respectively. Based on the results presented in Figure 5, it can be concluded that there was laxity in sample movement in Y2015 than in Y2014, creating a bottleneck in the FSL performance by affecting the commencement of laboratory analysis. This is an administrative process that requires attention.

\subsection{Laboratory Analysis Turnaround Time for Each FSL Discipline}

Figure 6 presents the average values of $T A T_{2}$ for each of the three FSL disciplines: forensic chemistry, biology/DNA and toxicology. The average $T A T_{2}$ value was highest for forensic biology/DNA, which was about 93.4 days (about 3 months). This value is too long, despite that it is comparable to data presented for American FSLs. The average value of $T A T_{2}$ for forensic chemistry and toxicology were 82.0 and 88.0 days respectively, which are still too long. All the average values are longer than the clients' service charter pledge of 14 days. This necessitates management efforts in turnaround time reduction.

Figure 7 shows the PDFs of $T A T_{2}$ data from the three laboratories for Y 2015. The PDF for forensic chemistry shows a very high peak at $T A T_{2}=10$ days, indicating that most of the analysis are completed within 14 days stipulated in the clients service charter. The PDF of $T A T_{2}$ data from Biology/DNA laboratory, on

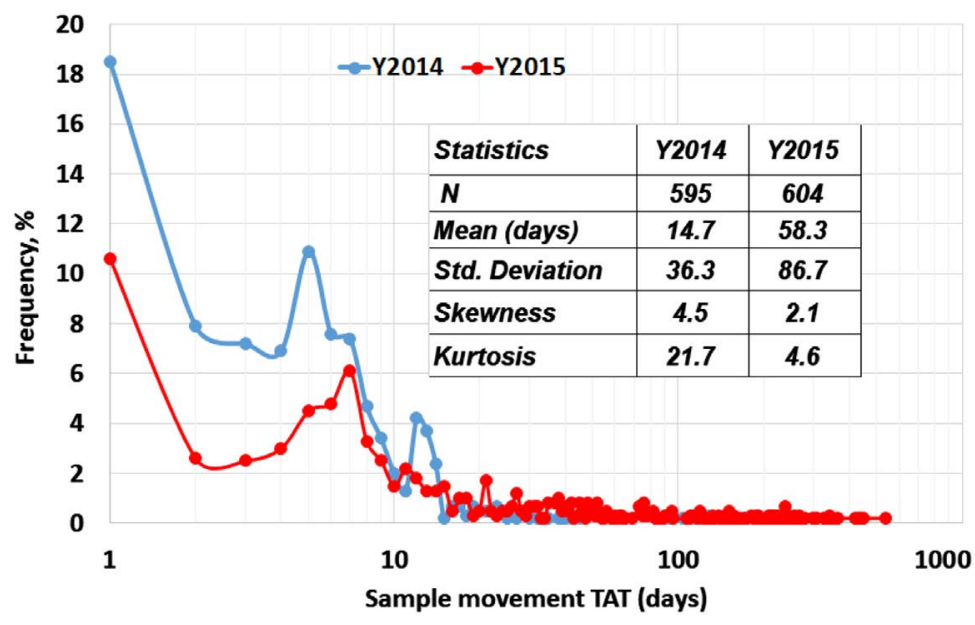

Figure 5. PDF of sample movement turnaround time (TATs) for Y2014 and Y2015. 


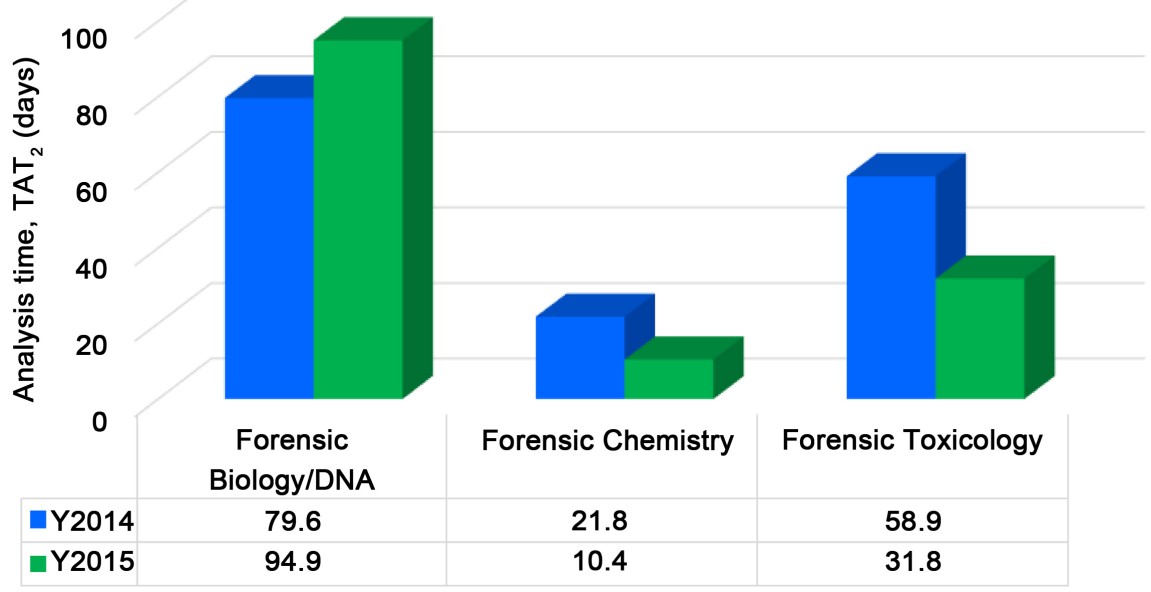

Figure 6. Comparison between average laboratory analysis turnaround time for different disciplines for Y2014 and Y2015.

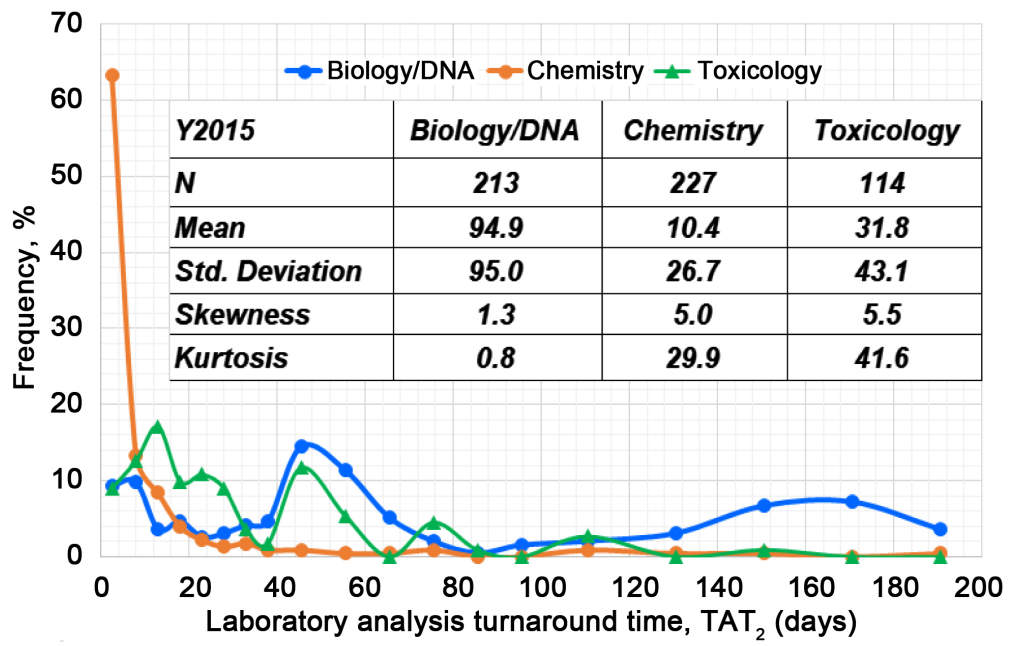

Figure 7. PDFs of $T A T_{2}$ data for specific FSL discipline (Y2015).

the other hand, is flatter, with long tail towards higher values. This laboratory shows two distinct peaks at $T A T_{2}=8$ and 45 days, attributable to the two different types of analysis requests submitted for DNA analysis, that is civil case samples whose analysis is normally completed faster and criminal samples (which take longer time to complete analysis). Similar to forensic biology/DNA, toxicology laboratory data shows two peaks one at $T A T_{2}=16$ days and another at 45 days. This also shows presence of two different types of samples submitted for toxicological analysis that is blood (with shorter TAT) and stomach contents (which take longer time due to intensive processes involved. It is interesting to note that the PDF for forensic biology/DNA and toxicology have very long tails extending to as long as 200 days which leads to frustration for both analysts and clients.

The $T A T_{2}$ data from all laboratory disciplines show high standard deviation, indicating that the analysis time varies widely between casefiles. The fluctuations 
in $T A T_{2}$ with time as case-files are processed indicate that the $T A T_{2}$ is neither reproducible nor repeatable. Together with the cause of variability stated above, the type of case-file, sample influx, machine availability and many other reasons, will cause such variations and differences in the $T A T_{2}$. As a result the management plans are continuously developed and implemented to reduce $T A T_{2}$, such as procurement of new machines or facilities, renovations, change of administrative procedures, improved staff skills within FSL and for police investigators and other requesting authorities, staff placement, improvements in supply chain management system, etc. A key measure of $T A T_{2}$ performance is customer satisfaction. For FSL, a customer is in high demand for timely analytical report. Thus, TAT should be optimized to minimize fluctuations so that TAT can be repeatable and reproducible over long run. Variable TAT may cause quality problems and customer dissatisfaction. In this work, the span of the TAT data (variability) was presented using cumulative probability density functions (CDFs) as shown in Figure 5.

Figure 8 shows the CDF of laboratory analysis time $\left(T A T_{2}\right)$ for 469 and 550 case-file received in 2014 and 2015, respectively. There were improvements in the $T A T_{2}$ in the forensic chemistry laboratory between Y2014 and Y2015, such that the percent of case-files analyzed within short time of 1 day or the same day $\left(T A T_{2}=0\right)$ increased to $40 \%$, attributable to completion of renovations in the laboratory, which applies also to the toxicology laboratory. Figure 8 shows also that the performance of biology/DNA laboratory dropped in Y2015, attributable to equipment failures.

Comparing the $\mathrm{CDF}_{\mathrm{S}}$ for $T A T_{2}$ data, it can be seen that they have the same

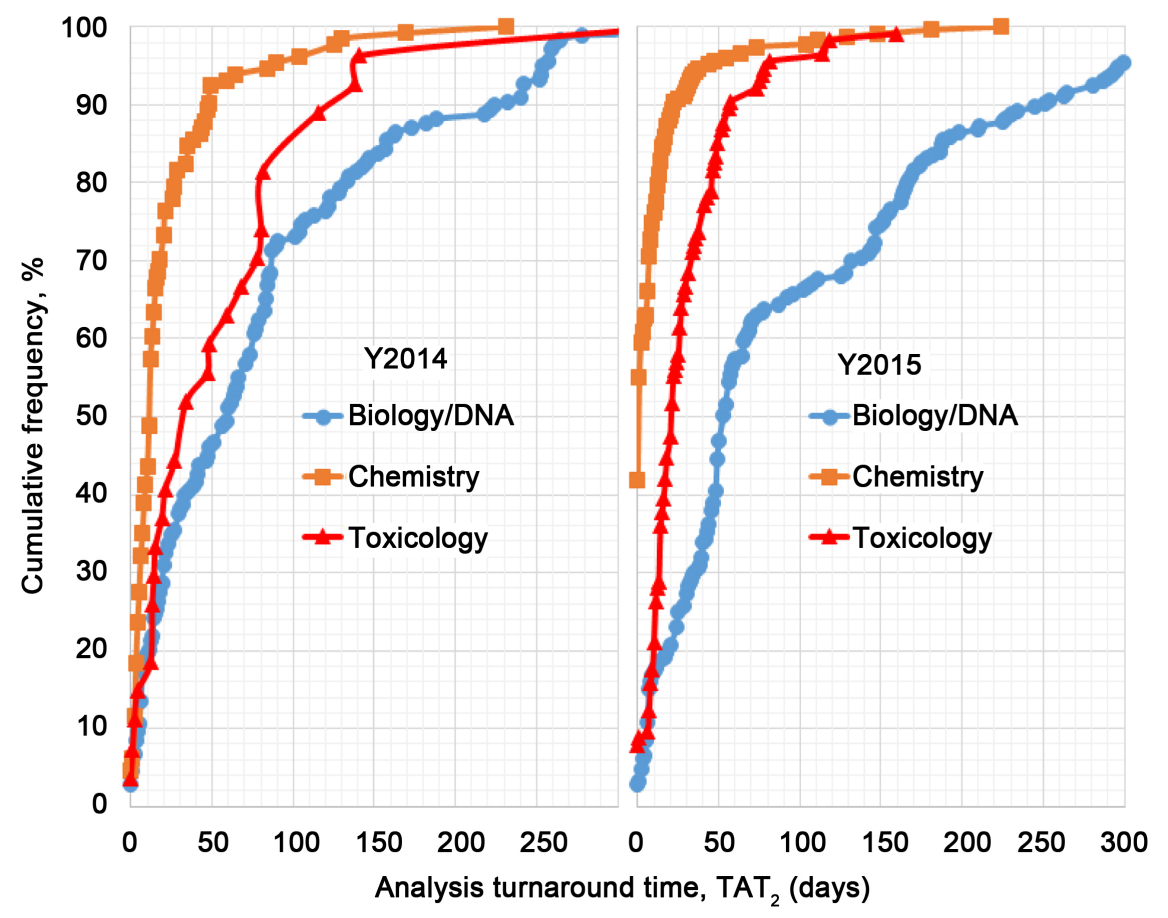

Figure 8. CDFs of all laboratories analysis turnaround time data. 
shape for 2014 and 2015 indicating that the time series emanate from a system affected by similar factors which did not change between the two years in all laboratories. The extended $T A T_{2}$ for biology/DNA laboratory can also be attributed to technical delays including difficulty with instrument such as malfunctioning of the instrument, sample resubmission delay, lack of competence among analysists and investigators, commitment of analysts, lack of supportive supervision, etc. Issues that arise from challenging samples, degraded or putrefied samples tend to produce abnormal results requiring verification (Steindel, 1995).

Based on Figure 7 and for data collected in Y2015, about 3\%, 7.9\% and $42 \%$ of case-files, are completed within the same day, while $15 \%, 12.3 \%$ and $70.5 \%$ of case-files are completed within 7 days in forensic biology/DNA, toxicology and chemistry laboratories. The GCLA clients' charter pledged 14 days, which corresponds only to $18.8 \%, 36 \%$, and $82.8 \%$ of completed case-files in the laboratory analysis process step for forensic biology/DNA, toxicology and chemistry laboratories, respectively, for data collected in Y2015.

A number of case-files are completed within short $T A T_{2}$ depending on the nature of the case-file, sample influx (Manyele, 2017) and type of samples, factors which cause difficulties, challenges and extended $T A T_{2}$. However, for forensic chemistry case-files, the $T A T_{2}$ is shorter compared to other forensic science laboratories due to the fact that the required results for responding to the prosecution require short process compared to forensic biology/DNA and toxicology. Moreover, samples submitted for forensic chemistry analysis are already in a chemical form most of the time as compared to biological samples submitted for biology/DNA and toxicology which are in a more complex molecular form and require extra procedures for obtaining the chemical components for further analysis. In addition, forensic chemistry reports do not require extra samples as reference for comparison and profiling of the results conducted in other forensic laboratory testing.

In biology/DNA laboratory, samples that are not associated with criminal issues, such as civil cases, analysis is performed within 7 - 14 days. Extended $T A T_{2}$ for forensic laboratory analysis is generally caused by diagnosis of the case-file itself. For instance, general paternity case is simple compared to those involving rape issues, murder, and drug of abuse combined in one case-file. Most requests that require short $T A T_{2}$ are those cases submitting samples of drugs of abuse. For such cases, the initial analysis results are good enough to satisfy the client and also give data that may be used to make decisions. In forensic chemistry, capacity building is much less complicated as tests are straight forward compared to the forensic biology/DNA discipline which requires multi-disciplinary subjects or parameters to master the field of analysis.

\subsection{Report Writing Time Turnaround Time}

Each FSL has specific requirements and procedures given in the respective dis- 
cipline of FSL regarding report writing (format, length and case analysis details). The laboratory report will address the specific legal requirements accordingly, and follow the general format guidelines, such as title with the laboratory identification number, name of analyst, reviewer and the name of person who authorizes the report. Also, it will have an introductory part and objectives, methods, results, discussion and conclusions. However, it should be noted that, the introductory part of the report illustrate the level of scientific progress involved, evaluation of which varies substantially among the three forensic science disciplines. Figure 9 compares the average values of $T A T_{3}$ for the three FSL laboratory disciplines for Y2014 and Y2014.

Biology/DNA reports took longest turnaround time (up to 10 days) compared to the forensic chemistry which took up to 3 days only on average, and forensic toxicology which took 1 day only. The extended turnaround time during report writing for forensic biology/DNA is acceptable as it involves careful interpretation of data generated by the Genetic Analyzer and careful interpretation to yield useful forensic conclusions. To achieve reduction in $T A T_{3}$ for forensic biology/DNA laboratory, increasing the number of analysts will be the best solution. Figure 10 shows the PDFs of report writing turnaround time data from the three laboratory disciplines for the two consecutive years. Comparing the $T A T_{3}$ data, the $\mathrm{PDF}_{\mathrm{s}}$ have the same shape for 2014 and 2015, indicating that the time series originates from a system that is affected by similar factors. The standard deviation and other statistics of the $T A T_{3}$ data remains the same for two years, with the former being the highest for biology/DNA laboratory. It was further observed that the PDFs follow a logarithmic scale with extended tails towards higher values of $T A T_{3}$. The highest frequency at $T A T_{3}=1$ day is an indication of good performance in all laboratories in the report writing stage.

Comparing the PDF from the two years, the maximum values for $T A T_{3}$ for the two years were observed to be too high, requiring reduction measures,

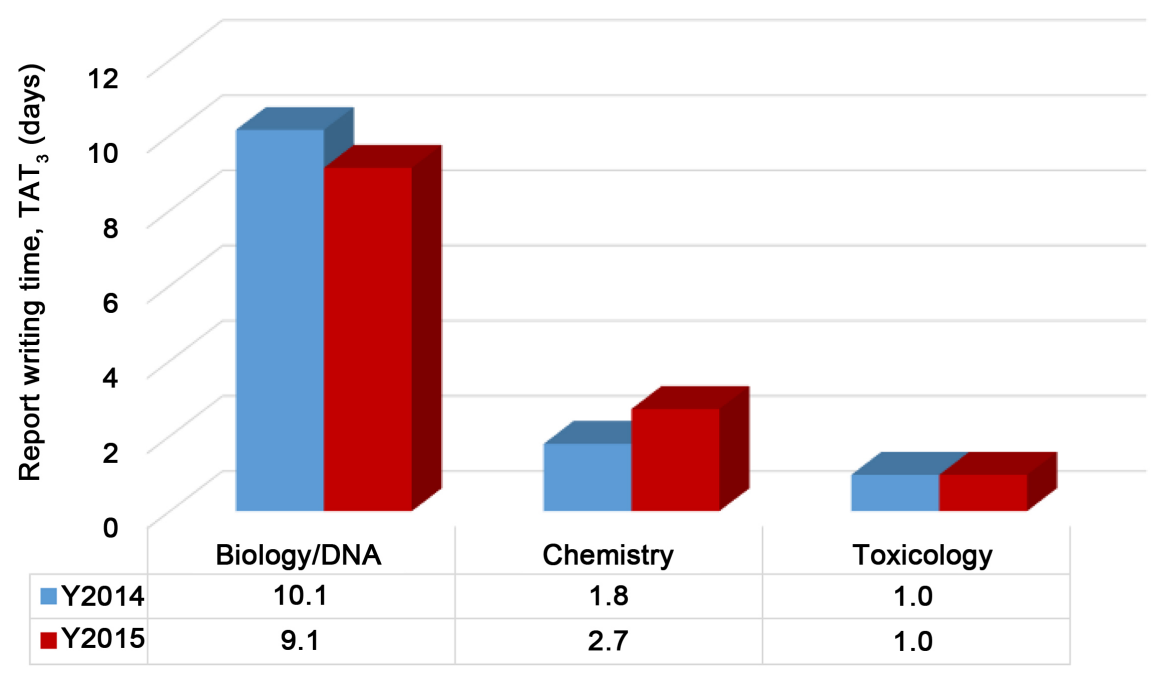

Figure 9. Comparison between average report writing turnaround times for different disciplines for Y2014 and Y2015. 

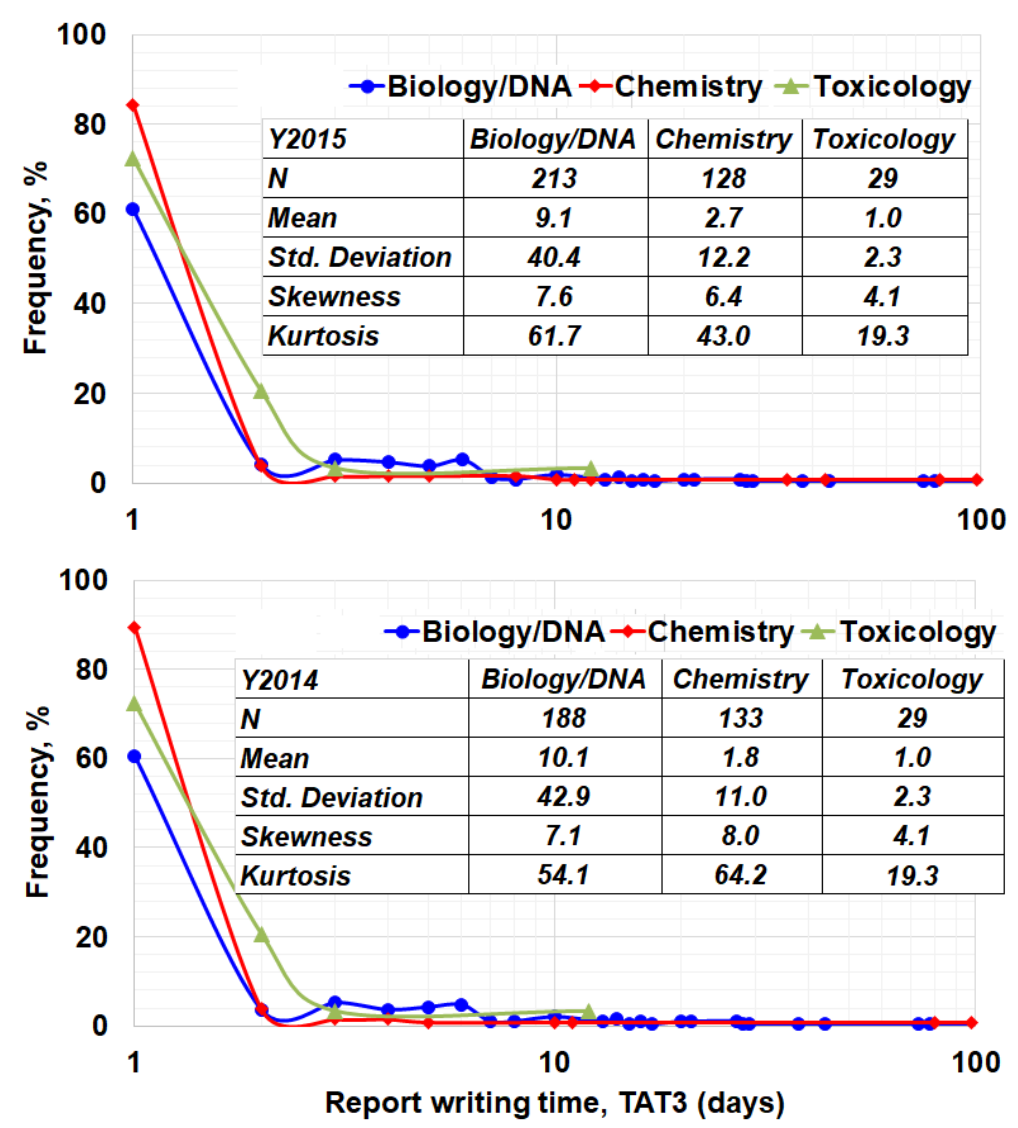

Figure 10. PDF of report writing turnaround time for different laboratory disciplines in two consecutive years.

despite that they appear at very low frequency. Moreover, the complexity of the case-file such as having too many samples and the need for comparing results in the case-file can lead to extended $T A T_{3}$. Such longer times can be minimized by in-house training (which is cost effective), involving customized content offered to analysts from time to time. Practices in report writing, will have a consistent quality improvement and convenience, and exposure to different cases of analytical results which require reports.

\subsection{Report Review Turnaround Time}

Laboratory report is one of the written communications within the scientific community and specifically between forensic laboratory and the judiciary. Moreover, understanding the components that generate a well written FSL report is essential. The study is meant to improve writing abilities among new FSL staff increasing the motivation, engagement and responsibility for timely review of forensic science laboratory reports. Review of the laboratory reports can be explained as a method of evaluating work performance and results, ability to enhance skills needed in the typical workforce, communication, and leadership, but also critical thinking skills and organizational competitiveness.

The report review turnaround time (denoted as $T A T_{4}$ ) comprises of the time 
when report writing is completed until when the report is submitted to the director for approval (as shown in Figure 1). In this study, it was observed that report review time, $T A T_{4}$, took approximately 3.0, 10.7 and 12.9 days on average for biology/DNA, chemistry and toxicology laboratories, respectively for 2015, as shown in Figure 11. Toxicology and chemistry laboratory reports took exceedingly too long to review than DNA reports, which is contrary to expectations. However, there are exceptional cases were the review takes longer, especially in cases of reports that are of high profile and require more scrutiny, which are always of criminal nature. The extended average $T A T_{4}$ for the year 2015 can be attributed to the report reviewers' absence while attending increased number of court sessions in 2015. This is because the laboratory managers and other gazetted scientists are required to provide expert witness in courts all over the country, leaving pending report to be reviewed. Moreover, analytical report drafters with lack of experience causes report review to take longer, as an on job training.

Figure 11 shows also the PDFs for $T A T_{4}$ data for the year 2015. Extended $T A T_{4}$ is still evident, whereby the values span beyond 5 days although at lowest frequency. Extended $T A T_{4}$ is caused by several reasons such as case-files with high number of samples, high profile cases, lack of time for reviewing the reports while attending court sessions for cases analyzed by FSL, cases that have samples of different discipline combined in one report but analyzed in different laboratories using different standard operating procedures (SOPs) and also the need for repeated tests and calculations when results are inconsistent. However, efforts are required to minimize $T A T_{4}$ within the FSL.

Consistency in terms of $T A T_{4}$ is still a problem in the FSL as shown by standard deviation values that are very high compared to the mean values, especially for biology/DNA laboratory and toxicology. Efforts to minimize $T A T_{4}$ and its

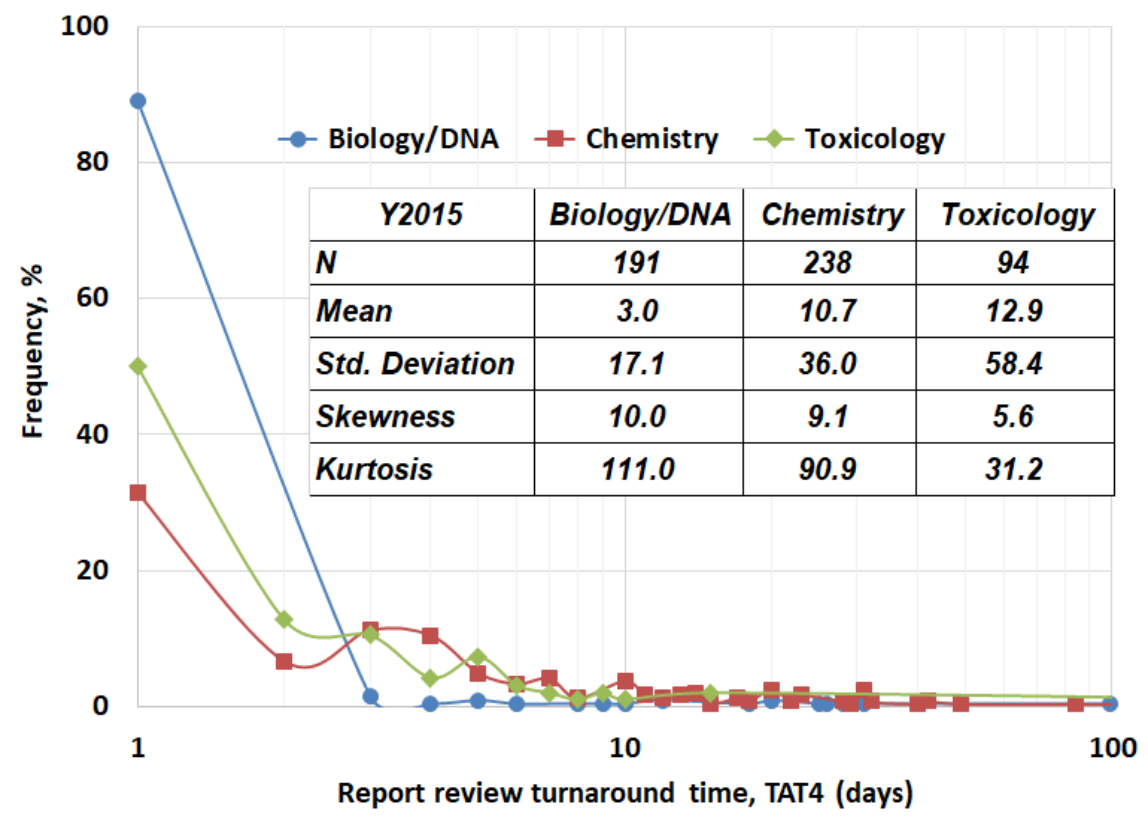

Figure 11. Report review processes time delay. 
variations via supportive supervision are required. Report review delay may be considered as the period that is determined when the laboratory manager reviews the issues related to the results by deep analysis and reasoning while focusing at solving the case in hand. It involves exercising skills in both technical and conceptual areas. This is when the manager has to observe if the actual equipment were used, appropriate protocols and procedures were adhered to and the costing was properly done as per tests conducted. In addition, the review will establish if the reports having the analytical results communicate with the management and the client or if it has enough information such that the similar work need not be repeated. It is noted that due to complexity of forensic science analytical work, if the necessary amount of sample submitted is not adequate or there is a need for re-submission of any other appropriate specimen for the specific tests reports remain without review. However, some literature state that it was difficult to capture the TAT for report review which is also known as "accessioning to results" since the reports were released in a computerized manner (Stotler and Kraz, 2012). This study however, has shown a possibility of capturing report review time ( $\left.T A T_{4}\right)$ using results submission forms.

\subsection{Final Report Approval Process Turnaround Time}

Final report approval process time delay $\left(T A T_{5}\right)$ comprises of the initial approval by the director followed by final approval from the CGC who is responsible for reports delivered by the FSL. This time starts when reviewed report is submitted to the director until the report is finally approved by CGC. The need for approval is mainly due to legal requirements and authentication of the reports used for courts and partly to provide the investigation team with authentic reports.

Figure 11 shows the PDF of final approval turnaround time data $\left(T A T_{5}\right)$ for 510 and 475 case-files from 2014 and 2015, respectively. The average values for $T A T_{5}$ were observed to be 25.9 days for year 2014 and 8.9 days for the following year. However, the $T A T_{5}$ is still high necessitating efforts for reduction of time day. In Figure 12, the exceedingly higher $T A T_{5}$ values for 2014 than 2015, are



Figure 12. The probability density function of final report approval turnaround time data for Y2015 and Y2014. 
revealed by long tails on the PDFs, while stronger fluctuations in the data as shown by high values of standard deviation for data from $2014(\sigma=75.1)$ than from $2015(\sigma=32.9)$. This is also supported by higher positive skewness for 2014 $\left(S_{k}=4.8\right)$ than from $2015\left(S_{k}=9.7\right)$. Moreover, the two PDFs have similar shapes for $T A T_{5}$ indicating that the factors influencing final report approval time delay were the same for two consecutive years. Thus, strong administrative decisions are needed to make improvements and reduce the $T A T_{5}$.

\subsection{Report Collection Turnaround Time}

Report collection time may be defined as the point in time starting after final approval by CGC until when the laboratory results collected by the clients. At this stage, all reports approved have to be recorded using a system which is not computerized. This leads to high workload causing delay especially the need for stamping and sealing reports before releasing the report to the SRO. The reports are supposed to be well prepared by CGC's office and SRO and are in a condition or available for the requesting authority or the client collection. This analysis stops when the report is actually collected. In this study results show that clients tend to delay in collecting their results for exceedingly longer times as observed in Figure 13.

Report collection turnaround time data shown in Figure 13 are still too long defeating the purpose of submission and request for analysis. Average values of $T A T_{6}$ equal to 26.5 days and 19.4 days were observed for Y2014 and Y2015, respectively. It should be noted also that these are completed reports waiting for collection only. It should be noted that the report collection delays are caused by factors external to FSL. The FSL clients have also their own practices and pressures with the investigation processes which cannot be controlled by the FSL. Proper communication between two entities is required, as this scenario affects the FSL competitiveness.

The need for completing paperwork or chain-of-custody documentation from

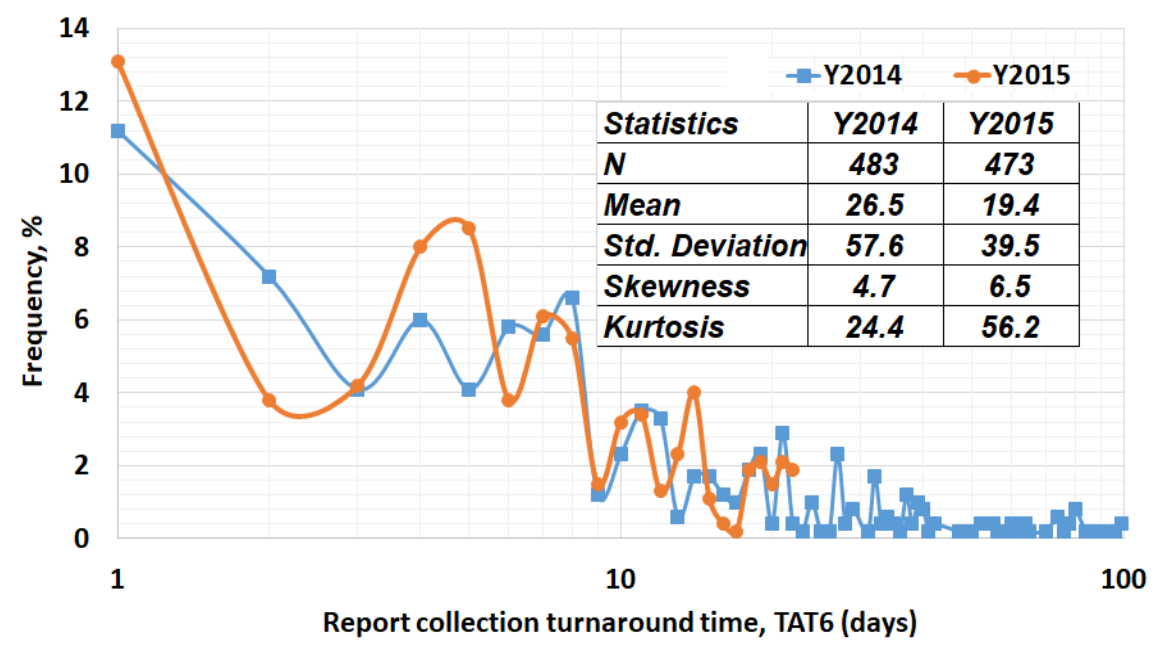

Figure 13. The probability density function data of report collection time delay. 
the requesting authority may result in extended report collection time. In addition to specifying who may receive the analytical results, the FSL requires the different disciplines of laboratories to have in place policies and procedures stipulating who should collect the results, leading to report collection delays. Also, adequate manual or electronic systems to ensure that test results and other specific data are accurately and reliably sent from the point of data entry to final report destination or to the requesting authority, in a timely manner are suggested.

\subsection{Analysis of Turnaround Times for Different Casefile Processing Steps}

Figure 14 compares the average TAT data for the six different processes in the FSL determined in this study. The results show that forensic biology/DNA laboratory has the most extended process TAT in laboratory analysis. Based on Figure 14, $T A T_{4}$ and $T A T_{5}$ for forensic toxicology and chemistry are the process steps that require action by the FSL management since they do not necessarily require longer turnaround times. Longer $T A T_{5}$ affects strongly the biology/DNA laboratory because it follows a 3 day review process hampering all the efforts. It is interesting to note that in Y2015 collection of completed analytical reports for forensic chemistry took the longest time among all process steps, that is, 19.4 days. Moreover, reducing $T A T_{3}$ for biology/DNA laboratory is critical when

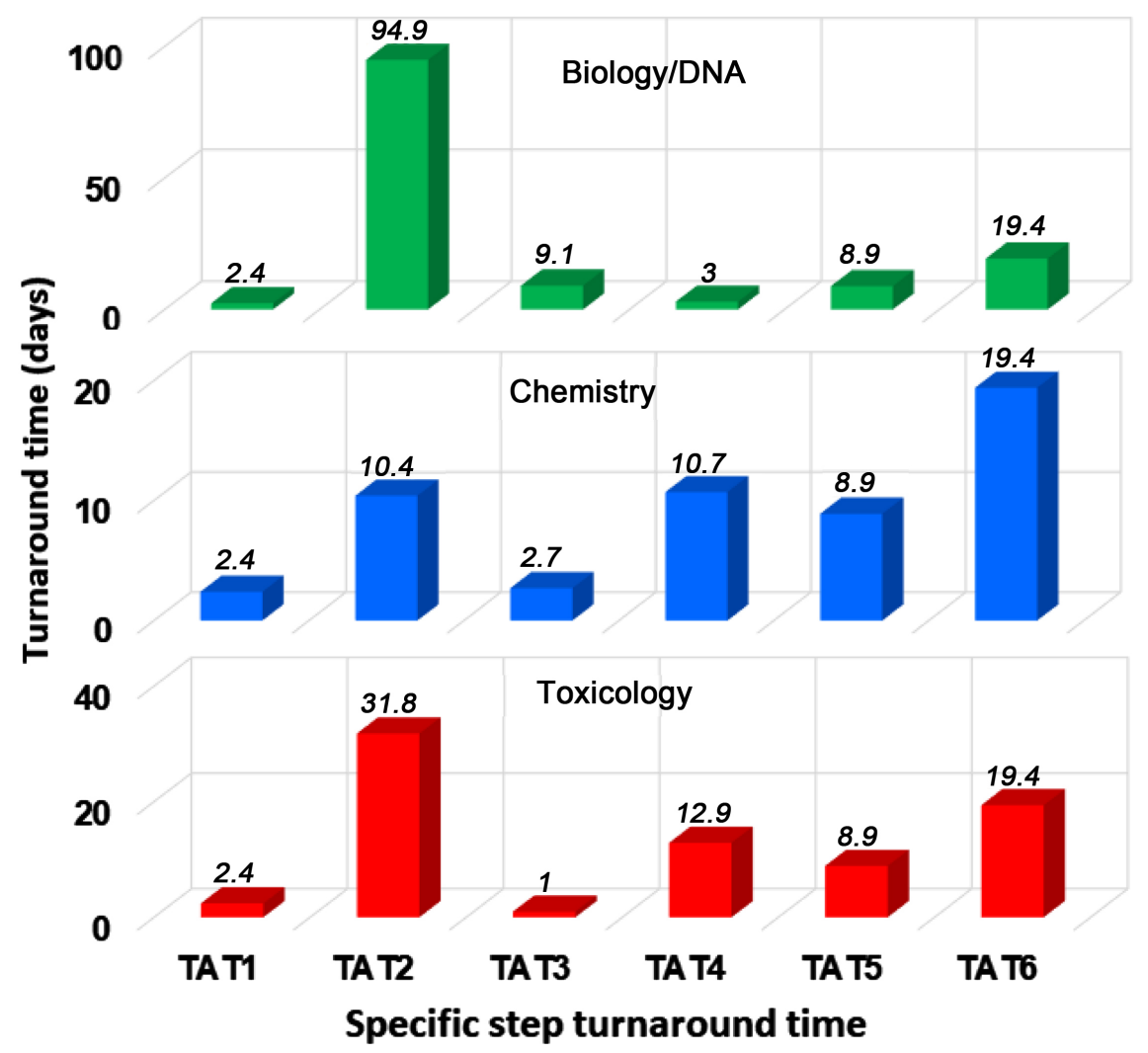

Figure 14. Average TAT for the six different case-file processing steps in the FSL (Y2015). 
compared to other laboratories disciplines which spend 2.7 and 1 day only.

Furthermore, different aspects may be the cause of extended TTAT for DNA compared to toxicology and forensic chemistry. Samples submitted to toxicology and chemistry can be accurately used for the identification of the chemical substance, while the extraction of DNA from the sample and its inherent success depends strongly on the part of the biological body where the sample originates. Presence of mixtures of DNA from a crime scene, and the biological materials collected at different crime scenes are never exposed to exactly the same conditions, therefore, the samples tend be challenging during processing, leading to extended $T A T_{2}$.

Severe degradation of the samples of DNA begins immediately after death. Which is one of the reasons analytical processes such as PCR are difficult for degraded materials that are commonly found at crime scenes. DNA in aged skeletal remains may be subjected to chemical modifications such as oxidative and hydrolytic damage. This is another major challenge when analyzing minute amounts of DNA from old skeletal remains which is a time consuming process. In addition, different approaches to remove or destroy contamination have been investigated.

In addition, for the case of forensic chemistry, several factors may be the source of time delay which includes samples received being masked with other materials that do not have drug of abuse characteristics. Also, samples may be received which are of a combination of different types of drugs known as cocktails of drugs. Other types of samples received are soaked with other organic substances such as tea leaves, coffee, cashew nuts, etc. For the case of forensic toxicology, samples may be received with inappropriate preservative, wrong sampled organ, or wrong timing of sampling depending on the incidence and samples that are received while deteriorated. All these aspects extend $T A T_{2}$ and hence extended TTAT.

\subsection{Analysis of Total Turnaround Time for Case-Files from Different FSL Disciplines}

The values of TAT available in the literature from the other forensic science laboratories in the World are quiet higher compared to these findings. The management of the respective forensic science discipline, regular quality assurance, meeting with the technical staff and strict adherence to policies and procedures are the strategic details of these low figures reported in this study. However, these low Figures do not justify the delays to be acceptable. The extended time delay prompted FSL to procure a new LC/MS/MS automated analyzer, and develop a competence plan so as to reduce significantly the TAT in the near future. A follow up study of similar nature with statistical analysis is required to prove the above hypothesis after installation of new equipment.

Regular audit of such data will help in the evaluation of the efficiency of the laboratory and hence corrective measures taken accordingly. This is important for providing better FSL service and hence increasing the competitiveness of the 
organization. By restructuring the pre and post-analytical processes, the TAT of the forensic science laboratories can be reduced (Chung et al., 2009). Figure 15 compares the values of total turnaround times TTAT from the three FSL disciplines for the Y2015. Generally, the TTAT for forensic biology/DNA was the highest compared to forensic toxicology and forensic chemistry attributable to longer $T A T_{2}$, causes of which were discussed above. This analysis comprises the TAT starting from the date a request is made to collection of the report. The average TTAT for each FSL, for the two years, as presented in Figure 14 shows that, in all consecutive years, TTAT for forensic biology and DNA have been extended. This may be due to the complexity of analysis and sensitivity of the samples that are received in this laboratory.

The analysis of the total turnaround times for each laboratory discipline leads to the consideration of the fraction of the TTAT comprised of laboratory analysis time. It can be seen in Figure 14 that the $T A T_{2}$ was the highest in the forensic biology/DNA and forensic toxicology, with exception of forensic chemistry where the exceedingly longer time was the report collection delay. The percentage pf the $T A T_{2}$ as a fraction of TTAT is also shown in Figure 15. While the $T A T_{2}$ comprise of $19.1 \%$ of the total turnaround time for forensic chemistry, results show that it comprised of $41.6 \%$ and exceedingly $68.9 \%$ for forensic toxicology and biology/DNA, respectively. Efforts for TTAT reduction should then focus on analysis turnaround time, for these two laboratories.

Based on Equation (3), the percentage of the theoretical turnaround time, $T A T_{\text {th }}$, was determined as shown in Figure 15. Results show that the percentage of $T A T_{\text {th }}$ is lower for forensic chemistry, at $60 \%$, indicating that $40 \%$ of the time of comprised of non-productive activities. The productive activities comprise a large fraction of the time for forensic biology/DNA ( $\left.T A T_{t h}=84.2 \%\right)$ and forensic toxicology $\left(T A T_{t h}=71.5 \%\right)$. Reduction of the report collection time will improve the performance of the FSL significantly.



Figure 15. Total turnaround time (TTAT) and percentage of its components $\left(T A T_{2}\right.$ and $\left.T A T_{t h}\right)$ for different FSL disciplines for Y2015. 


\subsection{Pareto Analysis for the TTAT for the Casefile Processing Steps}

Pareto analysis is a statistical analysis technique used in decision-making for the selection of a small number of factors contributing $80 \%$ of the problem or bottlenecks but which produce significant overall effect when solved by utilizing $20 \%$ of the available resources. It uses the Pareto Principle (also known as the $80 / 20$ rule). Once the predominant problems are identified, tools like the fish-bone analysis can used to identify the root causes of the problems. The application of Pareto analysis in this study combines all TTAT components from the time a request for analysis is submitted until report is collected, as shown in Figure 16. Note that the objective of this analysis was to identify key laboratory processes causing extended turnaround time in the three laboratory disciplines. Major target points to concentrate efforts were observed to differ between each laboratory discipline, that is, the list of TAT components contributing to $80 \%$ of the total turnaround time were different between the three laboratories. Using a horizontal line at a cumulative percent of $80 \%$, only one factor was identified for forensic biology/DNA that is, $T A T_{2}$. For the case of forensic chemistry, three steps were identified, that is $T A T_{6}, T A T_{4}$ and $T A T_{2}$, in this order. For the forensic toxicology laboratory, two steps were identified to cause extended turnaround time, that is, $T A T_{2}$ followed by $T A T_{6}$.

Using Venn diagram concept, it can be seen that $T A T_{2}$ forms a core problem of extended turnaround time for all the three laboratories, while $T A T_{6}$ affects mainly forensic chemistry and forensic toxicology. On the other hand $T A T_{4}$ affects only forensic chemistry. These are the three components which need to be solved in order to reduce total turnaround time for the FSL laboratories. However, report collection delay $\left(T A T_{6}\right)$ is caused by factors internal and external to FSL, so that its control must involve dealing with clients or staff external to FSL. Results show also that bottlenecks can differ from year 2014 to year 2015 based on the average values of $T A T_{2}$ from these two years (Figure 6). Thus, this analysis should be applied from time to time to identify true bottlenecks instead of

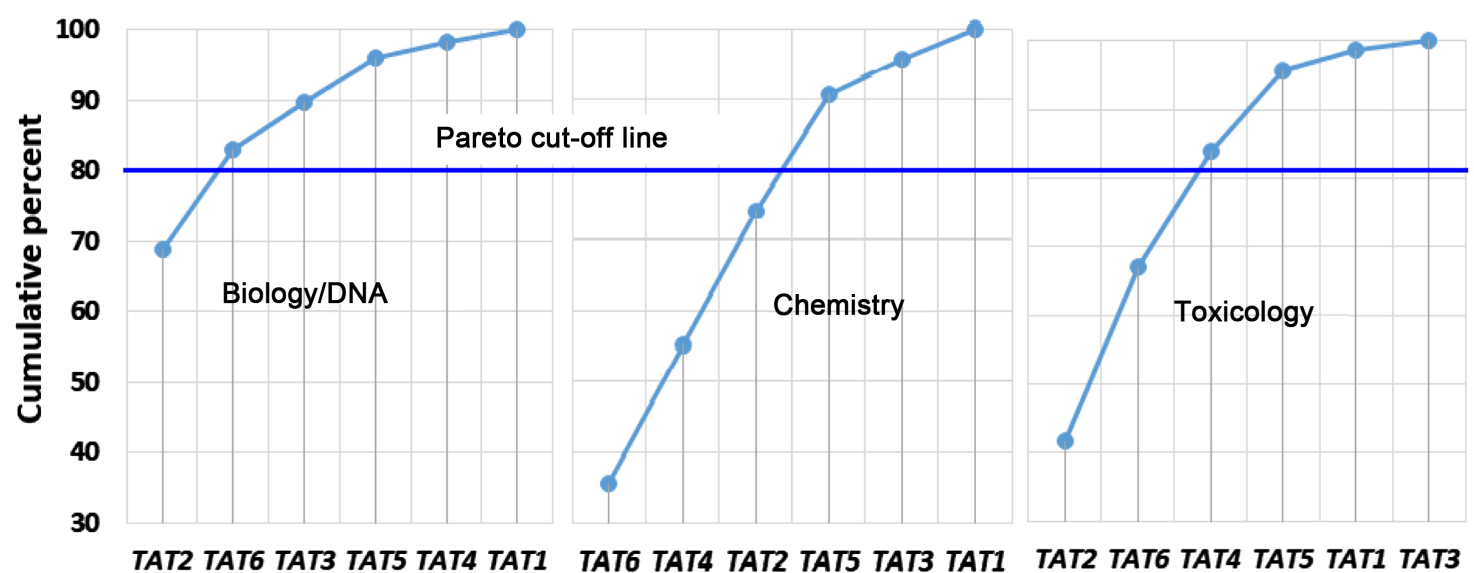

Figure 16. Pareto analysis diagram for the year 2015 showing challenges affecting TTAT and which have to be addressed first for each laboratory discipline. 
perceived ones.

\subsection{Root Cause Analysis for Extended Turnaround Time}

The extended TAT challenge can be explained in the form of product design and quality problem inhibition to detect potential factors causing an overall effect in FSL competitiveness. Cause-and-effect diagrams commonly known as fishbone diagram, showing factors and the root causes for critical factors affecting total TAT were used. The typical categories of factors include personnel, management, instrument and equipment, and supply chain processes. Figure 16 show that in this study the primary causes of extended TAT problem have been identified as the analysis turnaround time $\left(T A T_{2}\right)$, report collection delay and report review turnaround time. Table 3 however, shows the major causes of extended TAT identified above and some caused for delays in additional steps, based on fish bone classification system.

Table 3. Root cause analysis for extended turnaround time in the FSL.

\begin{tabular}{|c|c|c|}
\hline $\mathrm{S} / \mathrm{N}$ & $\begin{array}{l}\text { Bottlenecks in } \\
\text { the casefile } \\
\text { processing }\end{array}$ & Root causes \\
\hline 1 & $\begin{array}{l}\text { Extended } \\
\text { analysis } \\
\text { turnaround time } \\
\quad\left(T A T_{2}\right)\end{array}$ & $\begin{array}{l}\text { Delays due to SCM challenges, sample influx for casefiles } \\
\text { especially forensic chemistry, machine availability-due to } \\
\text { extended delay for service as a result of relying on } \\
\text { foreign/overseas service providers and forex, inadequate } \\
\text { scheduled staff for analysis especially processing the exhibits or } \\
\text { samples; sample quality and quantity } \\
\text { as a challenge which increases the rate of } \\
\text { reprocessing the exhibits or samples. }\end{array}$ \\
\hline 2 & $\begin{array}{c}\text { Report collection } \\
\text { delays }\left(T A T_{6}\right)\end{array}$ & $\begin{array}{l}\text { Lack of communication-no feed back to the client for any } \\
\text { inconveniences or report due for collection, in adequate } \\
\text { customer care management training, clients schedule, } \\
\text { transport for collection by client, request is from rural } \\
\text { areas which is far from the central FSL. }\end{array}$ \\
\hline 3 & $\begin{array}{l}\text { Extended report } \\
\text { review time } \\
\qquad\left(T A T_{4}\right)\end{array}$ & $\begin{array}{l}\text { Reviewers who laboratory managers and the director } \\
\text { being involved in expert witness sessions } \\
\text { Lack of large number of qualified and gazetted } \\
\text { analysts to perform review of reports }\end{array}$ \\
\hline 4 & $\begin{array}{l}\text { Initial } \\
\text { administrative } \\
\text { procedures } \\
\left(T A T_{1}\right)\end{array}$ & $\begin{array}{l}\text { Lack of computerized system in record management, } \\
\text { lack of trained personnel for record management, } \\
\text { inadequate computing facilities, inadequate working } \\
\text { space for keeping and categorizing the paper work }\end{array}$ \\
\hline 5 & $\begin{array}{c}\text { Report writing } \\
\text { time }\left(T A T_{3}\right)\end{array}$ & $\begin{array}{l}\text { Inadequate computing facilities leading to user queues } \\
\text { during report writing; inexperienced analysts in report } \\
\text { writing, lack of scheduled or periodic in-house training programs } \\
\text { for report writing skills; experienced staff in attendance } \\
\text { of court sessions keep incomplete reports pending; } \\
\text { lack of engagement among analysts, lack of motivation } \\
\text { and seriousness among experienced analysts. }\end{array}$ \\
\hline
\end{tabular}




\section{Conclusion}

Ensuring that the forensic test results are reported timely will assist in optimizing forensic science laboratory stakeholders and the criminal justice system at large. However, there are many challenges and factors that cause the extended time for any process within the forensic science laboratories. For instance, in this study, casefile in FSL are attended by analysts with different ranks leading to differences in turnaround times for analysis phase. Due to differences in SOPs, machines and procedures, different laboratories were observed to have different laboratory analysis turnaround time and hence different TTAT. More delays occur during laboratory analysis time $\left(T A T_{2}\right)$ compared to other steps. Thus, $T A T_{2}$ varies between case-files, between analysts of the same laboratory, and between different laboratory disciplines. The PDFs indicated wide variations in $T A T_{2}$ data with same shape for different years and for different laboratory disciplines. It was also observed that Forensic biology/DNA had the highest $T A T_{2}$. The PDFs of $T A T_{3}$ were similar between 2014 and 2015, and also among the three laboratories. Final report approval turnaround time, $T A T_{5}$, has the same pattern as that of report review process time $\left(T A T_{4}\right)$ which also decreased between 2014 and 2015. The report review, approval and collection turnaround time data were similar in shape and span, all contributing to the total TAT. More often, case reports are collected just after their completion, or in other words of writing the report, although extended delays have been observed to contribute to the total TAT. Forensic biology/DNA laboratory had the highest overall average total turnaround time (TTAT) among other FSL disciplines for the year 2015, while TTAT was the lowest for forensic chemistry. The time for initial administrative procedures $T A T_{1}$, contributed less to the total TAT for all laboratory disciplines. According to Pareto analysis for the six different case-file processing steps, the targets steps for reducing TAT are the analysis turnaround time $\left(T A T_{2}\right)$, report collection delays $\left(T A T_{6}\right)$ and extended report review time $\left(T A T_{4}\right)$. The $T A T_{6}$ reduction for this step may require communication strategies, awareness raising, stakeholders meeting and report delivery improvements, as it involved external clients.

\section{Acknowledgements}

The authors are grateful to the financial and technical support from the Government Chemist Laboratory Authority for sponsoring the study and permission to use the FSL as a study area. Special gratitude to the staff in the SROs office for their support during data entry.

\section{References}

[1] Hawkins, R.C. (2007) Laboratory Turnaround Time. Clinical Biochemist Reviews, 28, 179-194.

[2] Chung, H.-J., Lee, W., Chun, S., Park, H.-I. and Min, W.-K. (2009) Analysis of Turnaround Time by Subdividing Three Phases for Outpatient Chemistry Specimens. Annals of Clinical and Laboratory Sciences, 39, 144-149. 
[3] Hilborne, L.H., Oye, R.K., McArdle, J.E., Repinski, J.A. and Rodgerson, D.O. (1989) Evaluation of Stat and Routine Turnaround Times as a Component of Laboratory Quality. American Journal of Clinical Pathology, 91, 331-335. https://doi.org/10.1093/ajcp/91.3.331

[4] Howanitz, P.J., Cembrowski G.S. and Steindel, S.J. (1993). Physician Goals and Laboratory Test Turnaround Times. Archives of Pathology \& Laboratory Medicine, $117,22-28$.

[5] Steindel, S.J., Jones, B.A. and Howanitz, P.J. (1996) Timeliness of Automated Routine Laboratory Tests: A College of American Pathologists Q-Probes Study of 653 Institutions. Clinical Chimical Acta, 251, 25-40. https://doi.org/10.1016/0009-8981(96)06298-5

[6] Kenagy, J.W., Berwick, D.M. and Shone, M.F. (1999) Service Quality in Healthcare. Journal of the American Medical Association, 281, 661-665. https://doi.org/10.1001/jama.281.7.661

[7] Steindel, S.J. (1995) Timeliness of Clinical Laboratory Tests, a Discussion Based on Five College of American Pathologist Q-Probe Studies. Archives of Pathology \& Laboratory Medicine, 119, 952-61.

[8] Truchaud, A., Le Neel, T., Brochard, H., Malvaux, S., Moyo, M. and Cazaubiel, M. (1997) New Tools for Laboratory Design and Management. Clinical Chemistry, 43, 1709-1715.

[9] Kilgore, M.L., Steindel, S.J. and Smith, J.A. (1998) Evaluating Stat Testing Options in Academic Health Center: Therapeutic Turnaround Time and Staff Satisfaction. Clinical Chemistry, 44, 1597-1603.

[10] Kaur, V., Kamaljit, S., Minni V. and Chopra, B. (2015) Monitoring of Turnaround time (TAT) in Biochemistry Laboratory of a Tertiary Care Hospital in Punjab. Journal of Dental and Medical Sciences, 14, 9-12.

[11] Crook, M.A. (2000) Near Patient Testing and Pathology in the New Millennium. Journal of Clinical Pathology, 53, 27-30. https://doi.org/10.1136/jcp.53.1.27

[12] Manor, P.G. (1999) Turnaround Times in the Laboratory: A Review of the Literature. Clinical Laboratory Science, 12, 85-89.

[13] Weinstein, S. (1995) Quality in Pathology Laboratory Practice. Journal of Quality Clinical Practices, 15, 121-126.

[14] Bilwani, F., Siddiqui, I. and Vaqar, S. (2003) Determination of Delay in Turnaround Time (TAT) of Stat Tests and Its Causes: An AKUH Experience. Journal of Pakistan Medical Association, 53, 65-67.

[15] Howanitz, J.H. and Howanitz, P.J. (2001) Laboratory Results Timeliness as a Quality Attribute and Strategy. American Journal of Clinical Pathology, 116, 311-315. https://doi.org/10.1309/H0DY-6VTW-NB36-U3L6

[16] Carraro, P. and Plebani, M. (2002) Process Control Reduces the Laboratory Turnaround Time. Clinical Chemistry and Laboratory Medicine, 40, 421-422. https://doi.org/10.1515/CCLM.2002.068

[17] Huang, Y.W., Chen, W.H., Wu, H.J., Chien, H.Y., Lin, T.Y. and Chiang, H.H. (2003) Learning Curve of a New Hospital Laboratory: The Monitoring of Computer-Generated Turn-Around Time of Laboratory Tests in an Emergency Department. Clinical Chemistry and Laboratory Medicine, 41, 1373-1378. https://doi.org/10.1515/CCLM.2003.211

[18] Lewandrowski, K. (2004) How the Clinical Laboratory and the Emergency Department Can Work Together to Move Patients through Quickly. Clinical Leadership Management Review, 18, 155-159. 
[19] Fernandes, C.M., Worster, A., Eva, K., Hill, S. and McCallum, C. (2006) Pneumatic Tube Delivery System for Blood Samples Reduces Turnaround Times without Affecting Sample Quality. Journal of Emergency Nursing, 32, 139-143. https://doi.org/10.1016/j.jen.2005.11.013

[20] Westbrook, J.I., Georgiou, A., Dimos A. and Germanos, T. (2006) Computerized Pathology Test Order Entry Reduces Laboratory Turnaround Times and Influences Tests Ordered by Hospital Clinicians: A Controlled before and after Study. Journal of Clinical Pathology, 59, 533-536. https://doi.org/10.1136/jcp.2005.029983

[21] Chien, T.I., Lu, J.Y., Kao, J.T., Cheng, Y.C. and Lee, Y.F. (2007) Evaluation and Improvement Strategy of Analytical Turnaround Time in the Stat Laboratory. Journal of Formos Medical Association, 106, 558-564.

https://doi.org/10.1016/S0929-6646(07)60006-0

[22] Steindel, S.J. and Novis, D.A. (1999) Using Outlier Events to Monitor Test Turnaround Time. Archives of Pathology \& Laboratory Medicine, 123, 607-614.

[23] Rollo, J.L. and Fauser, B.A. (1993) Computers in Total Quality Management: Statistical Process Control to Expedite Stats. Archives of Pathology \& Laboratory Medicine, 117, 900-905.

[24] Holland, L.L., Smith, L.L. and Blick, K.E. (2005) Reducing Laboratory Turnaround Time Outliers Can Reduce Emergency Department Patient Length of Stay. American Journal of Clinical Pathology, 124, 672-674. https://doi.org/10.1309/E9QPVQ6G2FBVMJ3B

[25] Howanitz, P.J. and Steindel, S.J. (1991) Intralaboratory Performance and Laboratorians' Expectations for Stat Turnaround Times: A College of American Pathologists Q-Probes Study of Four Cerebrospinal Fluid Determinations. Archives of Pathology \& Laboratory Medicine, 115, 977-983.

[26] Watts, N.B. (1995) Reproducibility (Precision) in Alternate Site Testing: A Clinician's Perspective. Archives of Pathology \& Laboratory Medicine, 119, 914-917.

[27] Neuberger, J. and Peters, M. (1996) The Clinical Interface-A British Physician's View. Clinical Chimical Acta, 248, 11-18. https://doi.org/10.1016/0009-8981(95)06262-9

[28] Steindel, S.J. and Howanitz, P.J. (2001) Physician Satisfaction and Emergency Department Laboratory Test Turnaround Time. Archives of Pathology \& Laboratory Medicine, 125, 863-871.

[29] Steindel, S.J. and Howanitz, P.J. (1997) Changes in Emergency Department Turnaround Time Performance from 1990 to 1993: A Comparison of Two College of American Pathologists Q-probes Studies. Archives of Pathology \& Laboratory Medicine, 121, 1031-1041.

[30] Howanitz, P.J. (2005) Errors in Laboratory Medicine: Practical Lessons to Improve Patient Safety. Archives of Pathology Laboratory Medical, 129, 1252-1261. 